\title{
Stripe assay to examine axonal guidance and cell migration
}

\author{
Bernd Knöll $^{1}$, Christine Weinl ${ }^{1}$, Alfred Nordheim ${ }^{1}$ \& Friedrich Bonhoeffer ${ }^{2}$ \\ ${ }^{1}$ Interfaculty Institute for Cell Biology, Department of Molecular Biology, University of Tübingen, Auf der Morgenstelle 15, 72076 Tübingen, Germany. ${ }^{2}$ Max-Planck- \\ Institute for Developmental Biology, Spemannstrasse 35, 72076 Tübingen, Germany. Correspondence should be addressed to B.K. (bernd.knoell@uni-tuebingen.de).
}

Published online 10 May 2007; doi:10.1038/nprot.2007.157

\begin{abstract}
Stripe assays have been widely employed as in vitro test systems to study the responses of growing axons, as well as migrating cells, to established or novel guidance molecules. We provide detailed protocols for both the original and the modified version of this assay, as they allow the analysis of the 'guidance properties' of active components present in crude membrane fractions or as purified molecules. Silicon matrices are used to produce striped patterns of active molecules on a surface (referred to as 'carpet'), followed by culturing of neurons, or any other cell type, on these carpets. After 1-2 days in culture, striped outgrowth of extending neuritesindicative of guided migration of cell processes-can be observed. We also discuss potential other applications (e.g., in neuronal regeneration and development) and modifications of the assay. The preparation of 10-12 carpets takes approximately 4-5 h.
\end{abstract}

\section{INTRODUCTION}

The stripe assay was originally designed by F. Bonhoeffer and co-workers ${ }^{1,2}$ in the late 1980 s to analyze fundamental axonal guidance mechanisms governing the formation of the topographic map established in the chick retino-tectal system (for review, see ref. 3). Employing this assay, the presence of a graded distribution of repulsive axon guidance cues, present predominantly in posterior tectal membranes, was discovered. Subsequently, this assay was modified, permitting the identification of ephrin-As as the key components present in posterior membranes that are responsible for the repulsive properties ${ }^{4-7}$.

The stripe assay has since been used to uncover guidance cues and mechanisms in many principal neuronal projections, including, for example, the hippocampal, thalamic and olfactory systems ${ }^{8-11}$. The stripe assay was also applied to investigate neurite outgrowth and guidance behavior related to neuronal regeneration $^{12-15}$ and branch formation ${ }^{16}$. Furthermore, the stripe assay has proven valuable in dissecting signaling cascades initiated downstream of axonal guidance receptors activated by ligands printed in a striped pattern ${ }^{12-15}$. In addition, the guidance properties of membrane-tethered molecules as well as the short-range action of secreted guidance molecules (such as Slits and Semaphorins) could be mimicked in vitro by this assay ${ }^{17,18}$. Also stripe assay experiments were conducted to unravel potential guidance properties of extracellular matrix components ${ }^{19,20}$ and of cell adhesion molecules of the IgG superfamily ${ }^{21}$.

Of note, the stripe assay was employed as an in vitro assay to investigate the navigation responses of both axonal growth cones toward guidance cues and of migrating cells $s^{4,22,23}$. With respect to the latter, neural crest cells ${ }^{22}$ and oligodendrocytes ${ }^{23,24}$, but also non-neuronal cells such as tumor cells, have been studied ${ }^{25}$.

The assay allows assessment of guidance activity of established molecules and also testing potential guidance properties of hitherto uncharacterized molecules such as RGM, the Wnt signaling inhibitor SFRP1 or the morphogen Sonic hedgehog ${ }^{26-28}$.

Besides the widely used stripe assay consisting of straight individual stripes, other geometric patterns-such as zig-zag patterns-have been employed ${ }^{29}$. These zig-zag stripes are valuable when analyzing cell behavior and signal-transduction events at substrate borders, where, for example, one part of a cell is adhering to a laminin substrate and the other part is contacting a substrate of different molecular nature ${ }^{30}$. Also, a novel technique allowing for microcontact printing of proteins on surfaces has been reported and offers a versatile tool to study the behavior of, for example, navigating growth cones in gradients of axon guidance cues $^{31}$.

In the experimental setup, striped carpets are produced with the aid of specially manufactured silicon matrices to glass, plastic or nucleopore membrane surfaces.

These matrices consist of a channel system, which can be filled with a solution containing the guidance cue under investigation.

The original version of the assay employed stripes generated with crude membrane fractions of tissue (e.g., a certain brain area) or of cells transfected with the guidance molecule of interest. These crude membrane fractions are then sucked in a striped pattern onto polycarbonate nucleopore filters by application of vacuum.

The modified stripe assay allows one to examine the 'guidance properties' of purified molecules. Here, matrices are attached to either glass coverslips or plastic Petri dishes, which provide a solid and even surface to prepare the striped pattern. The choice of using either a coverslip or a Petri dish is at the experimenter's convenience. A detailed protocol is given for plastic Petri dishes, but glass coverslips have been used regularly and successfully by other investigators (see, e.g., ref. 18). After attaching the matrix to the Petri dish, the matrix channels are filled with the molecules of interest and thereby establish the set of first stripes (see Figs. 1-3). After incubation, the matrix is removed and the gaps between the first stripes are filled with a solution containing control molecules, thereby generating the set of second stripes. This experimental regimen results in alternating stripes consisting of guidance cue ("first stripes") and control molecule ("second stripes"). To distinguish the set of first stripes from the neighboring second stripes, the first stripe solution contains fluorescently labeled antibodies or beads. To provide a general growth-promoting environment, laminin (or any other extracellular matrix component) is homogeneously applied to the carpets. After adding, for example, neurons on top of these carpets and allowing 1-2 days of culture 
Figure 1 | Original version of the stripe assay. (a) Experimental setup to produce alternating stripes of membrane fragments. Four suction filters mounted on a suction filter plate are connected to a vacuum pump via a non-return valve. Closing the hole (at black triangle) of the valve by inserting an Eppendorf tube leads to an increase of the pressure in the channel system ( -800 to $-1,000$ mbar; 'high vacuum'). Removal of this tube decreases the pressure ( -200 to -400 mbar; 'low vacuum'). (b) Detailed view of the suction filter plate illustrating the mounting of the matrices on the suction filters. Two filters are covered with white matrices (left side) to produce the set of first stripes. The other two filters, covered with blue matrices (right side), are used for generating the set of second stripes. Clips marked with white stars should always be closed when vacuum is to be generated. Clips on top are either closed (during changing nucleopore filters) or open (during generation of the striped pattern by applying vacuum or during washing steps). The dotted and dashed rectangles on the white and the blue matrix, respectively, indicate the position taken for the higher magnifications depicted in (c) and (e). (c) Higher magnification of a white matrix showing the channel system. Scale bar, $100 \mu \mathrm{m}$. (d) Electron microscopic picture of the white matrix channel system at even higher magnification. Scale bar, $350 \mu \mathrm{m}$. (e) Higher magnification of the blue matrix used to prepare the second stripes, depicting the innermost white mesh and the surrounding blue silicon base. Scale bar, $100 \mu \mathrm{m}$. (f) Even higher magnification of (e) highlighting the mesh-like structure of the innermost part of the blue matrix. Scale bar, $100 \mu \mathrm{m}$.

time for neurite outgrowth/cell migration, stripe assay results can be evaluated. Preferential growth on the set of first (fluorescent) stripes demonstrates the presence of an attractive guidance cue on these stripes, whereas growth on the second stripes (containing the control molecule) is indicative of a repulsive activity of the guidance molecule placed on the first stripes. On top of that it should be kept in mind that a 'repulsive activity' as observed in the stripe assay could be due to a general non-permissive substrate property of the molecule under investigation. To demonstrate an active repulsive turning away of an individual growth cone from a local source of the guidance cue, the turning assay is widely employed within the axon guidance field (see ref. 32).

Herein we give a detailed outline of the stripe assay procedures using the chick retino-tectal projection. This protocol was adapted by various research groups for their experimental designs and, for these modifications, we would like to refer throughout the manuscript to the relevant primary research literature $5,6,9,10,14,18,33$. First we describe the guidance behavior of axons from chick retinal ganglion cells (RGCs) growing on carpets consisting of alternating membrane fractions derived from anterior and posterior chick optic tecta (original version, Step 1A of PROCEDURE). Second, a protocol describing the modified version of the stripe assay is provided (Step 1B of PROCEDURE), whereby alternating stripes of
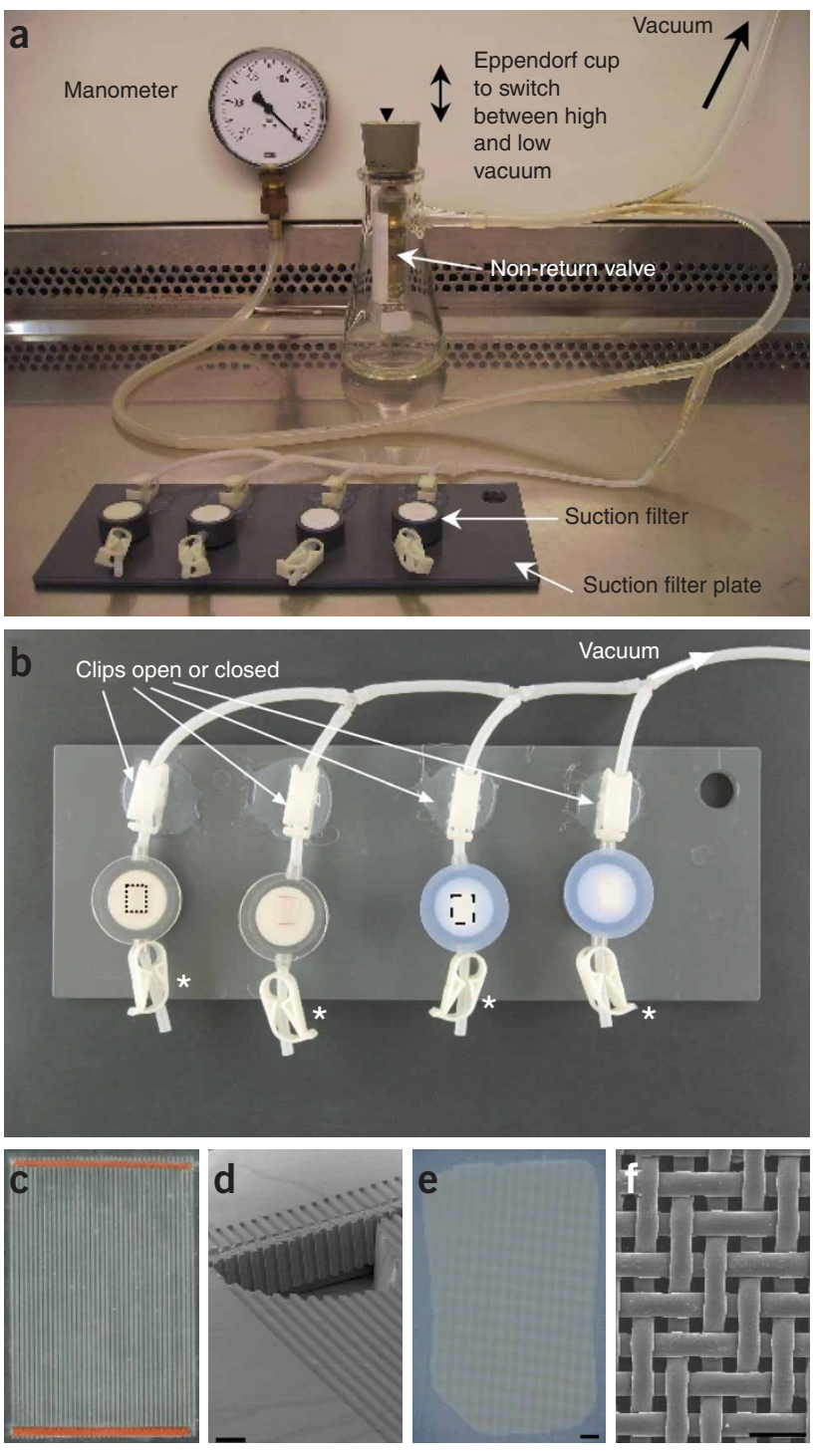

ephrinA5-Fc fusion proteins ('first stripes') and control stripes consisting of Fc alone ('second stripes') are prepared. Ephrin-As proteins trigger predominantly growth cone repulsion by activating EphA receptor tyrosine kinases on retinal axons ${ }^{34,35}$. Therefore, RGC axons are repelled by the set of first stripes containing ephrinA5, leading to axonal growth congruent with the control set of second stripes.

\section{MATERIALS}

\section{REAGENTS}

-Animals/embryos: E6 and E9 white Leghorn chick embryos for preparation of RGC cultures and tectal membranes, respectively ! CAUTION All animal experiments must comply with national regulations.

-Anti-human IgG, Fc-specific (Sigma, cat. no. I2136)

-Anti-human IgG, Fc-specific Cy3-conjugated (Sigma, cat. no. C2571)

- Aprotinin (Sigma, cat. no. A1153)

- EphrinA5-Fc, human (R\&D systems, cat. no. 374-EA)

- Fc (Calbiochem, cat. no. 401104)

- Fluorescent microspheres, $0.5 \mu \mathrm{m}$, for example red fluorescent (Molecular Probes, cat. no. F-8812)

- Hank's balanced salt solution (HBSS; without $\mathrm{Ca}^{2+}$ and $\mathrm{Mg}^{2+}$ (Invitrogen; cat. no. 14170-088)
- Laminin (mouse, Invitrogen, cat. no. 23017015)

- Leupeptin (Sigma, cat. no. L2884)

- Methanol

- PBS sterile (Invitrogen; cat. no. 14190), add $1 \times$ penicillin/streptomycin

- Pepstatin (Sigma, cat. no. P4265)

- Spermidine (Sigma, cat. no. S2501)

- SDS, $2 \%$ solution in $\mathrm{H}_{2} \mathrm{O}$

- Sucrose

\section{EQUIPMENT}

- $60 \mathrm{~mm}$ bacterial Petri dishes (Greiner, cat. no. 628102)

- Centrifuge, suitable for Falcon tube placement

- Cell scraper

- Falcon tubes, 15 and $50 \mathrm{ml}$ 
Figure 2 | Modified version of the stripe assay. (a) Silicon matrix used to produce stripe patterns using purified proteins. Arrows point toward the inlet channel and the outlet hole. Scale bar, $0.5 \mathrm{~cm}$. (b) Silicon matrices shown in (a) are pressed firmly with channels facing downwards (arrow) onto the surface of a Petri dish. (c) Margins of the stripes are marked on the bottom of the dish. (d) Illustration of method (a) to generate stripe patterns by injecting solution into the inlet channel with the help of a Hamilton syringe. The injected solution slowly fills and passes the channels and the excess volume exits at the outlet hole. During injection, the matrix is constantly pressed onto the dish surface. (e) Alternative method (b) of producing striped patterns by the use of suction. A volume of $100 \mu \mathrm{l}$ of the first solution is pipetted onto the so-called 'outlet hole' and vacuum is applied at the 'inlet' channel. (f) After 30 min of incubation at $37^{\circ} \mathrm{C}$, excess solution is removed by washing with HBSS (method a or b). Excess liquid at the outlet hole is removed. (g) Starting at the upper right corner, the matrix should be lifted off the Petri dish and removed quickly. (h) A volume of $100 \mu \mathrm{l}$ of second stripe solution is applied to the delineated area. Special care has to be taken not to touch or scrape the carpet surface with the pipette tip. Therefore, the solution is applied from one corner of the marked area. Subsequent washing steps and application of laminin or culture medium are performed in a similar way. The stripe pattern is encircled with a Pap-pen to reduce the volume of culture medium required.

- Hamilton syringe (Hamilton)

- Laminar flow hood

- Needle 26G, $0.45 \mu \mathrm{m}$

- Silicon matrices (see EQUIPMENT SETUP)

- Pap-pen (Invitrogen, Abcam) $\triangle$ CRITICAL Test Pap-pen for cytotoxicity before use.

- Polycarbonate Nucleopore membranes, $0.1 \mu \mathrm{m}$ (Whatman, cat. no. 112105). Cut nucleopore membrane into rectangles (approximately $1.5-1.7 \mathrm{~cm} \times 1.2$
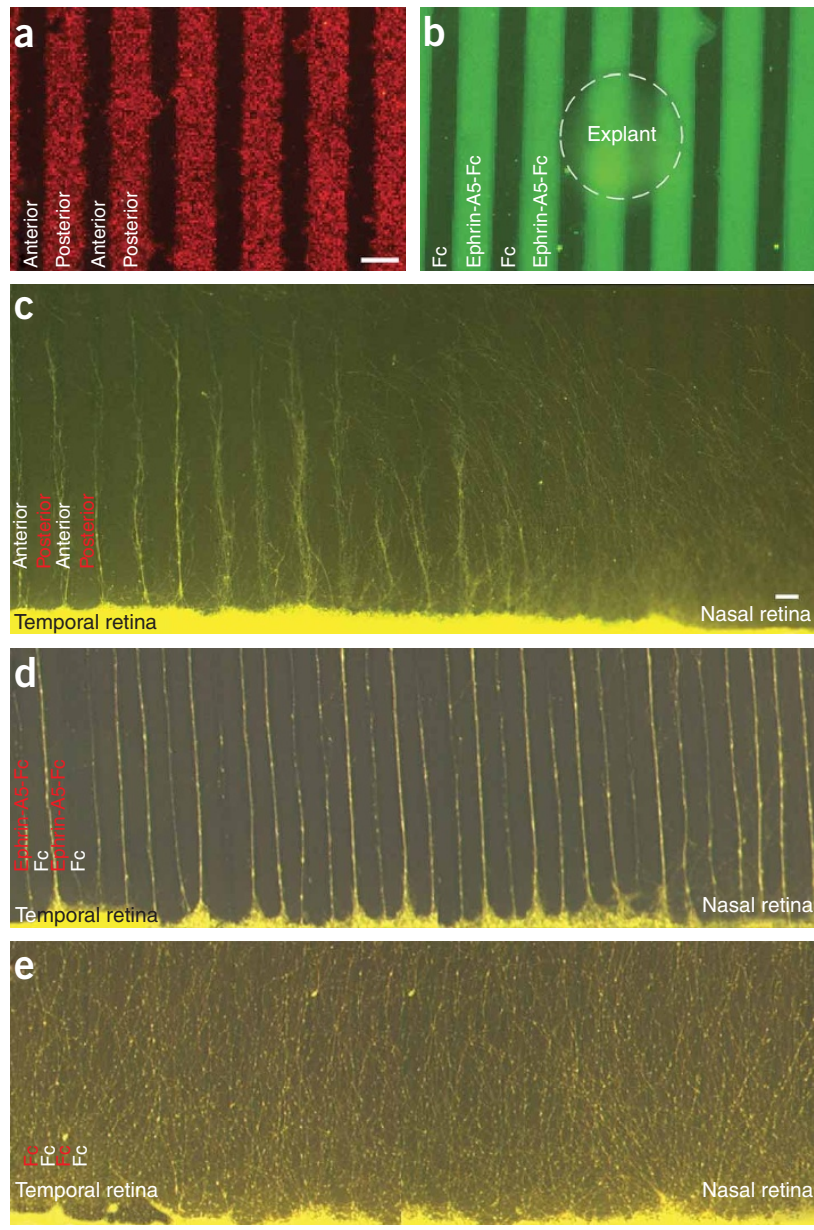
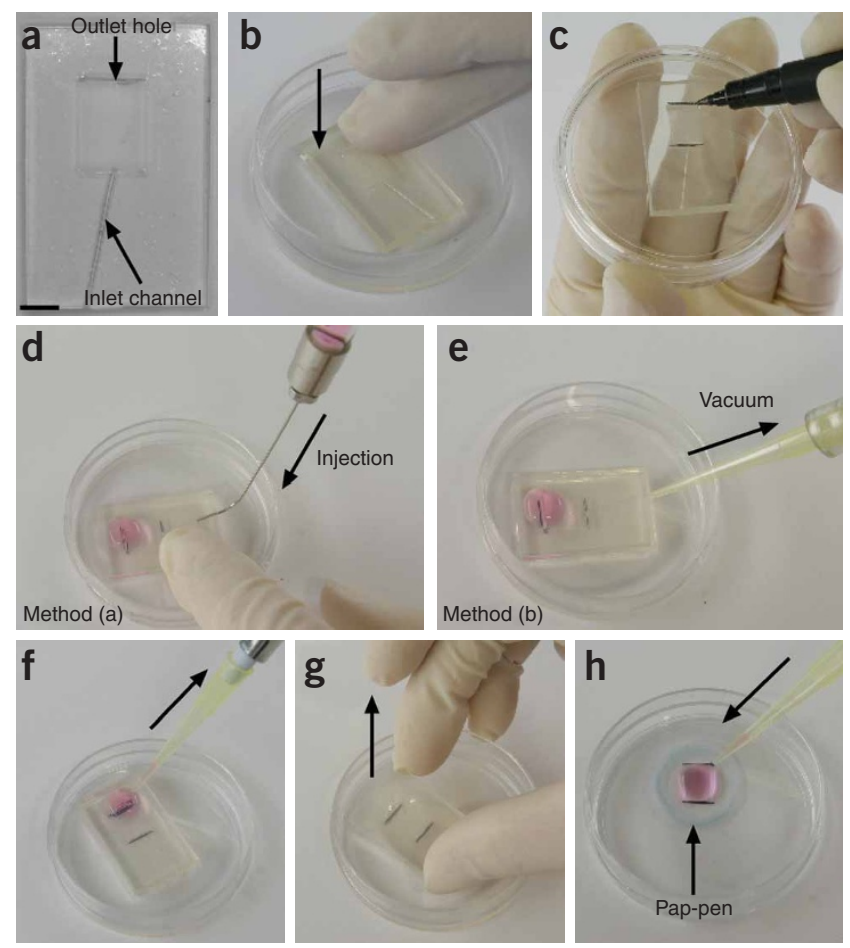

$1.4 \mathrm{~cm}$ ). Label rectangles by cutting the upper left corner with shiny side facing upwards

- Rotor tubes, $1.5 \mathrm{ml}$ (Beckman)

- Spectrophotometer (Pharmacia Ultraspec3000), $1 \mathrm{ml}$ quartz curvette

- Syringes, $1 \mathrm{ml}$

- Ultracentrifuge (TL-100 Beckmann with TLS-55 rotor)

-Equipment for suction apparatus: vaccum source (e.g., vacuum pump, laboratory bench vacuum); bottle; non-return valve fitting in bottle; tubing to connect bottle, plastic clips to close tubing (e.g., VWR), vacuum pump, suction filter plate and manometer

\section{REAGENT SETUP}

Homogenization buffer $(\mathrm{HB}) \quad 10 \mathrm{mM}$ Tris/ $\mathrm{HCl}, \mathrm{pH} 7.4,1 \mathrm{mM}$ spermidine $\times 3$ $\mathrm{HCl}$ and $1.5 \mathrm{mM} \mathrm{CaCl}{ }_{2} \cdot 2 \mathrm{H}_{2} \mathrm{O}$. Store at $4{ }^{\circ} \mathrm{C}$.

Aprotinin Dissolve $25 \mathrm{mg}$ in $4.2 \mathrm{ml}$ autoclaved $\mathrm{H}_{2} \mathrm{O}$, store aliquots at $-20{ }^{\circ} \mathrm{C}$; final concentration $200 \mathrm{U} \mathrm{ml}^{-1}$.

Leupeptin Dissolve $25 \mathrm{mg}$ in $26.3 \mathrm{ml}$ autoclaved $\mathrm{H}_{2} \mathrm{O}$, store aliquots at $-20^{\circ} \mathrm{C}$; final concentration $50 \mathrm{mM}$.

Pepstatin Dissolve $25 \mathrm{mg}$ in $18 \mathrm{ml}$ methanol, store aliquots at $-20{ }^{\circ} \mathrm{C}$; final concentration $2 \mathrm{mM}$.

$\mathbf{5 0 \%}(\mathrm{w} / \mathrm{w})$ sucrose solution Dissolve $50 \mathrm{~g}$ of sucrose in $50 \mathrm{~g}$ homogenization buffer, sterile-filter $(0.4 \mu \mathrm{m})$ and store at $-20{ }^{\circ} \mathrm{C}$

$\mathbf{5 \%}(\mathrm{v} / \mathrm{v})$ sucrose solution Dilute $50 \%$ sucrose solution 1:10 in homogenization buffer.

\section{EQUIPMENT SETUP}

Silicon matrices Silicon matrices and additional equipment for the stripe assay are presently distributed exclusively by the laboratory of Dr. Martin Bastmeyer

Figure 3 | Typical stripe patterns obtained. (a,b) Typical patterns of stripes obtained with the original method (a) (red stripes) and with the modified method (b) (green stripes). The circle in (b) delineates the position of an explant on top of this carpet. Scale bar, $100 \mu \mathrm{m}$. (c) Result of an original stripe assay experiment. Temporal RGC axons are repelled by posterior membranes (red) leading to growth on stripes derived from the anterior optic tectum. In contrast, nasal RGC axons are not repelled by posterior membranes thus growing randomly. Scale bar (c-e), $100 \mu \mathrm{m}$. (d) Result of a modified stripe assay experiment. Alternating stripes of ephrinA5-Fc (red) and $\mathrm{Fc}$ alone were prepared. Both temporal and nasal RGC axon populations are repelled, thus growing on the non-labeled dark set of second stripes. (e) Result of a control experiment of the modified stripe assay. All stripes consist of Fc alone, resulting in random RGC axon outgrowth. 
(Zoologisches Institut, Universität Karlsruhe, Germany) (bastmeyer@bio.uka.de). For the original version of the stripe assay outlined in Step 1A of PROCEDURE, four white matrices to prepare the set of first stripes, four blue matrices to prepare the set of second stripes and the suction filter plate are required (see also
Fig. 1). For the modified version of the stripe assay, outlined in Step 1B of PROCEDURE, the number of matrices (see Fig. 2a) required equals the number of carpets to be analyzed in one experiment. Regularly, we prepare up to 12 carpets in one experiment.

\section{PROCEDURE}

1) In the following steps we describe the procedure for the original version of the stripe assay in $(A)$ and the modified version of the stripe assay in (B). For the stripe assay using purified proteins rather than crude membrane fractions ${ }^{1}(B)$, a modified protocol of the initially published work is employed ${ }^{4,36}$. In option $B$ we describe a protocol preparing carpets of purified proteins belonging to the ephrin-A family of repulsive axon guidance molecules ${ }^{34,35}$. Ephrin-As are commercially available as fusion proteins (see MATERIALS section), containing the Fc part of the human IgG. Oligomerizing (so-called 'Clustering') of Ephrin-A-Fc with anti-Fc-specific IgG enhances the repulsion towards cells and growth cones by ephrin-A5. In principle, there are two options to produce stripes using the modified version of the stripe assay: injection of first stripe solution with a Hamilton syringe into the inlet channel (Fig. 2d) or by applying vacuum at the 'inlet channel' to suck solution through the channel system (Fig. 2e).

$\triangle$ CRITICAL STEP All steps, if not indicated otherwise, are performed in a laminar flow hood.

(A) Stripe assays using crude membrane fractions (original version)

(i) Preparations before starting. Boil (for $5 \mathrm{~min}$ ) and store blue and white matrices in autoclaved $\mathrm{H}_{2} \mathrm{O}$.

(ii) Boil (for $5 \mathrm{~min}$ ) and store precut nucleopore filters in autoclaved $\mathrm{H}_{2} \mathrm{O}$.

(iii) Coat the boiled nucleopore filters with $20 \mu \mathrm{g} \mathrm{ml} \mathrm{l}^{-1}$ laminin (in HBSS) and incubate for at least $1 \mathrm{~h}$ at $37^{\circ} \mathrm{C}$. Before use, wash with $1 \times$ HBSS and store in PBS.

$\triangle$ CRITICAL STEP Thaw laminin slowly on ice (approximately $1 \mathrm{~h}$ ) to prevent formation of aggregates.

(iv) Prepare PBS with protease inhibitors (hereafter called PBS+) by adding $250 \mu \mathrm{l}$ leupeptin, $100 \mu \mathrm{l}$ aprotinin and $10 \mu \mathrm{l}$ pepstatin to $10 \mathrm{ml} \mathrm{PBS}$; store at $4^{\circ} \mathrm{C}$ (prepare freshly for each experiment).

(v) Prepare homogenization buffer with protease inhibitors (hereafter called HB+) by adding $125 \mu \mathrm{l}$ leupeptin, $50 \mu \mathrm{l}$ aprotinin and $5 \mu \mathrm{l}$ pepstatin to $5 \mathrm{ml}$ homogenization buffer; store at $4{ }^{\circ} \mathrm{C}$ (prepare freshly for each experiment).

(vi) Thaw $50 \%$ sucrose solution, prepare $5 \%$ sucrose solution and store on ice.

(vii) Sterilize $1.5 \mathrm{ml}$ rotor tubes under UV light for $10 \mathrm{~min}$.

(viii) Preparation of crude membrane fractions. Prepare crude membrane fractions as a source of guidance molecules. As an example, in the following steps, we describe the preparation of membrane fractions from the anterior and the posterior thirds of six optic tecta of three E9 chick embryos. This amount of tissue represents approximately a total of 40-60 mg of cell material. The optimal amount of starting material has to be determined according to the individual experimental design. Alternatively, membrane fractions harvested of tissue culture cells transfected with a guidance cue of interest can be used (see ref. 5).

(ix) Wipe the surface of chick egg with $70 \%$ ethanol and open the chick egg with blunt forceps.

(x) Transfer the embryo into a Petri dish with HBSS.

(xi) Remove the pia mater and dissect the two underlying tecta.

(xii) Cut each tectum in three parts, discard the middle part and collect the anterior and the posterior thirds of both tecta in $\mathrm{HB}+$ separately.

(xiii) Wash the tectal thirds with $500 \mu \mathrm{l}$ cold $\mathrm{HB}+$.

(xiv) Add $600 \mu \mathrm{l}$ fresh $\mathrm{HB}+$ and homogenize tissue several times using a $1 \mathrm{ml}$ syringe with a $26 \mathrm{G}$ needle.

$\triangle$ CRITICAL STEP Avoid formation of air bubbles during homogenization. Homogenize slowly, that is, allow approximately $5-10 \mathrm{~s}$ for $600 \mu \mathrm{l}$ homogenate to pass through syringe.

(xv) Sucrose gradient centrifugation. This and the following steps describe sucrose gradient centrifugation, which will remove nuclei and cytoplasmic proteins and retain, for example, cytoplasmic and mitochondrial membrane fragments in the supernatant. First pipet $350 \mu \mathrm{l}$ of $50 \%$ sucrose solution into a $1.5 \mathrm{ml}$ rotor tube.

(xvi) Layer slowly $150 \mu \mathrm{l}$ of $5 \%$ sucrose solution on top.

(xvii) Load a maximum of $800 \mu$ l homogenized membranes on top of the $5 \%$ sucrose cushion. The maximal amount of homogenate that can be separated represents the anterior/posterior thirds of three E9 embryos. When using transfected cells, for example HEK293 cells, the homogenate of four $10 \mathrm{~cm}$ dishes can be loaded ${ }^{5}$.

(xviii) Centrifuge at 52,000 gor $10 \mathrm{~min}$ at $4{ }^{\circ} \mathrm{C}$ using the TLS-55 rotor in a Beckmann TL-100 centrifuge. Meanwhile prepare Eppendorf tubes with $1 \mathrm{~mL}$ PBS+ and store on ice.

(xix) After centrifugation, carefully remove the tubes from the rotor. Verify-by visual inspection-the presence of a white layer at an intermediate position in the rotor tube, which contains the crude membrane extract.

(xx) Carefully transfer the white intermediate phase into the tube with $1 \mathrm{~mL}$ PBS+.

(xxi) Centrifuge again to remove the remaining sucrose for 7 min at $13,000 \mathrm{~g}$ at $4{ }^{\circ} \mathrm{C}$.

(xxii) Discard the supernatant and resuspend the pellet in $1 \mathrm{ml}$ cold PBS+ with the syringe and $26 \mathrm{G}$ needle. 
(xxiii) Measurement of membrane fraction concentration. Add $20 \mu \mathrm{l}$ of each sample to $980 \mu \mathrm{l}$ of $2 \%(\mathrm{w} / \mathrm{v})$ SDS solution (prepare duplicates). Pipette $20 \mu \mathrm{l} \mathrm{PBS}+$ to $980 \mu \mathrm{l} 2 \%$ SDS as reference. Determine OD at $220 \mathrm{~nm}$ in a spectrophotometer using a quartz curette.

(xxiv) Multiply average $0 D_{220 n m}$ value by 3.33 to get the final $0 D_{220 n m} \cdot 10 D_{220 n m}=700 \mu \mathrm{g} \mathrm{ml} \mathrm{l}^{-1}$. The average $0 \mathrm{D}_{220 \mathrm{~nm}}$ value of three $\mathrm{E9}$ tecta resuspended in $1 \mathrm{~mL}$ PBS+ (see above) is approximately 0.2 .

- PAUSE POINT Aliquots of membrane fractions can be stored at $-80{ }^{\circ} \mathrm{C}$ or in liquid nitrogen for several weeks, up to 1 month. Upon thawing, the activity should be measured again and those membranes should not be frozen again. We recommend to continue without delay, as membrane fractions lose some activity upon storage.

(xxv) Dilute membrane fractions with cold PBS+ to an $0_{220 n m}$ of 0.1 and store on ice. Prepare $150 \mu \mathrm{l}$ of membrane solution for preparing one set of first stripes and $300 \mu \mathrm{l}$ of solution for preparation of one set of second stripes. As an estimate, adjusted membrane fractions with an $0_{220 n m}$ of 0.1 contain approximately $60-70 \mu \mathrm{g}$ protein per $\mathrm{ml}$ as determined by Bradford assay.

(xxvi) Label the first stripe solution with fluorescent beads by diluting $10 \mu \mathrm{l}$ of beads in $500 \mu \mathrm{l} \mathrm{PBS}+$. For $1 \mathrm{ml}$ of membrane solution, add $50 \mu \mathrm{l}$ of the diluted beads.

(xxvii) Preparation of carpets. Set up the vacuum-sucking device according to Figure 1a. Use sterile blunt forceps to handle matrices and nucleopore membranes.

(xxviii) Preparation before getting started with stripe preparation. Sterilize the suction filter plate by spraying with $70 \%$ $\mathrm{EtOH}$; rinse individual suction filters with PBS (see Fig. 1b).

(xxix) Check the vacuum with all four clips closed: at 'low' vacuum: -200 to -400 mbar (no Eppendorf tube in the bottle; see Fig. 1a); and at 'high' vacuum: -800 to $-1,000$ mbar (insert Eppendorf tube in the bottle). Closing or opening a hole in the bottle lid with the Eppendorf cup allows for switching between low and high vacuum.

(xxx) Prepare $10 \mathrm{~cm}$ dishes with individual PBS+ drops to store each nucleopore membrane on top after the first stripes have been prepared. The PBS+ drop underneath the membrane will prevent the membranes from drying out.

(xxxi) Prepare $35 \mathrm{~mm}$ Petri dishes with one drop of PBS+ in the middle to store carpets after preparation of second stripes.

(xxxii) Preparation of first stripes. Cover each suction filter with one white matrix and rinse all matrices with $1 \mathrm{ml}$ of PBS. Red lines of white matrix should be facing upward (see Fig. 1b,c).

(xxxiii) Close all clips.

(xxxiv) Add one nucleopore membrane on each of the four suction filters, with the marked corner of the membrane oriented to the upper left side (shiny surface faces downwards).

(xxxv) Pipette $150 \mu \mathrm{l}$ of first stripe solution on each of the four nucleopore membranes.

(xxxvi) Open clips, and apply high vacuum by closing the hole of the vacuum bottle with an Eppendorf tube.

(xxxvii) Start timer at -600 mbar and allow to suck for $90 \mathrm{~s}$.

(xxxviii) Remove excess liquid and stop high vacuum by removing the Eppendorf tube.

(xxxix) Leave low vacuum until stripes are visible on filter surface.

(xl) Immediately close clip and transfer all four nucleopore membranes on PBS+ drops in the Petri dish.

(xli) The quality of the first set of stripes can be quickly checked by fluorescence microscopy.

(xlii) Wash the white matrices before mounting the next nucleopore membranes by opening clips and rinsing with $1 \mathrm{~mL}$ of PBS. $\triangle$ CRITICAL STEP Do not allow nucleopore membranes to dry out at any time.

(xliii) Preparation of second stripes. Wash the suction filters three times with $1 \mathrm{ml}$ of PBS by applying vacuum.

(xliv) Add one blue matrix on each suction filter (in either orientation).

(xlv) Lift the blue matrix slightly at the edge and suck with $1 \mathrm{~mL}$ PBS+ underneath.

$\triangle$ CRITICAL STEP Make sure blue matrices are lying completely flat on suction filters (no air bubbles underneath).

(xlvi) Transfer nucleopore membranes (stored on PBS+ drop) onto suction filters.

(xlvii) Immediately add $150 \mu \mathrm{l}$ of second stripe solution and open clip; leave low vacuum until all four clips are opened.

(xlviii) Apply high vacuum (insert Eppendorf tube) and suck for $90 \mathrm{~s}$ once -600 mbar is reached.

$\triangle$ CRITICAL STEP Do not allow nucleopore membranes to dry out at any time.

(xlix) Rinse nucleopore membranes with $1 \mathrm{ml}$ of PBS+.

(l) Close clip and stop the high vacuum (remove Eppendorf tube).

(li) Transfer processed nucleopore membranes to individual $35 \mathrm{~mm}$ Petri dishes (with a drop of PBS+ at the bottom).

(lii) Add one drop of tissue culture medium onto the nucleopore membrane.

PAUSE POINT Store dishes at $37{ }^{\circ} \mathrm{C}$ and use on the same day (i.e., as soon as cells are ready to be cultured on carpets).

(B) Stripe assays (modified version) using purified proteins

(i) Preparations before starting experiment. Remove dust from matrix stripe surface with transparent tape. Boil matrices for 5-10 min in autoclaved $\mathrm{H}_{2} \mathrm{O}$ and dry overnight with striped pattern facing upwards in a laminar flow hood.

$\triangle$ CRITICAL STEP Matrices should be completely dry before being used. 
(ii) Sterilize $60 \mathrm{~mm}$ bacterial dishes under UV for 5-10 min.

(iii) Thaw laminin aliquot slowly on ice.

$\triangle$ CRITICAL STEP This step has to be performed slowly on ice to prevent formation of aggregates (approximately $1 \mathrm{~h}$ ).

(iv) Rinse Hamilton syringe with ethanol, followed by autoclaved $\mathrm{H}_{2} \mathrm{O}$ and $\mathrm{HBSS}$ between individual experiments. Sterilize outside by UV.

(v) Preparation of solutions and Petri dishes. For every carpet, prepare $100 \mu$ solution in HBSS for each of the first and second stripes. For preparation of the first stripes, two solutions are required: one ephrin-A5-containing solution for the experimental situation (1. stripe: ephrin-A5-Fc versus 2. stripe: $\mathrm{Fc}$ ) and one Fc-containing solution for the control setting (1. stripe: $\mathrm{Fc}$ versus 2. stripe: $\mathrm{Fc}$ ). For the second stripes, only one solution containing $\mathrm{Fc}$ alone has to be prepared (see also controls in Box 1). First stripe solution: ephrin-A5-Fc or Fc, $10 \mu \mathrm{g} \mathrm{ml}^{-1}$. Anti-human-IgG Fc-specific Cy3 conjugated, $2.5 \mu \mathrm{g} \mathrm{ml}^{-1}$. Second stripe solution: $\mathrm{Fc}, 10 \mu \mathrm{g} \mathrm{ml}^{-1}$. Anti-human-IgG Fc-specific, $2.5 \mu \mathrm{g} \mathrm{ml}^{-1}$. For alternative concentrations, see refs. 33,36. The approximate active concentration when testing novel proteins is recommended to be within a range of 1-30 $\mathrm{mg} \mathrm{ml}^{-1}$. Spin down anti-human-IgG, Fc-specific antibodies (Cy3-conjugated and unconjugated) before use $\left(1-2 \mathrm{~min}, 13,000 \mathrm{~g}, 4^{\circ} \mathrm{C}\right)$.

$\triangle$ CRITICAL STEP Without centrifugation, antibodies might produce aggregates resulting in unspecific guidance responses.

(vi) Preincubate first and second stripe solutions for 30 min under moderate agitation to allow for oligomerization of ephrinA5-Fc; keep solutions with Cy3-conjugated antibodies in the dark.

(vii) Prepare Petri dishes with matrices meanwhile by adding one matrix with channels facing downwards in the middle of a $60 \mathrm{~mm}$ bacterial Petri dish (see Fig. 2b). Label margins of stripes using a marker pen at the bottom of the dish (Fig. 2c).

$\triangle$ CRITICAL STEP Remove any air bubbles between matrix and dish surface, as this may cause leakage of solution.

(viii) Preparation of the first set of stripes. Prepare the first set of stripes by applying first stripe solution to the matrices. There are two possible methods: in the first (injection with a Hamilton syringe), insert the bent tip of a Hamilton syringe into the inlet channel of one matrix and inject slowly $100 \mathrm{ml}$ of the first stripe solution (Fig. 2d). The solution should slowly pass the stripe channels and leave the matrix opposite to the inlet channel. In the second method (using a vacuum), add $100 \mu \mathrm{l}$ of first stripe solution on outlet hole and suck solution through the channels by applying vacuum at inlet channel (Fig. 2e). It is critical to leave a small drop covering the outlet channel to prevent drying out.

(ix) Once all matrices of all dishes have been injected with first stripe solution, incubate all dishes for 30 min at $37{ }^{\circ} \mathrm{C}$ in a moist chamber to prevent drying out of stripes.

\section{BOX 1 | CONTROLS IN STRIPE ASSAY EXPERIMENTS}

\section{Controls in the original version of the stripe assay}

In Figure 3c, we illustrate the response of temporal and nasal axons in the original version of the stripe assay. Temporal and nasal axons exhibit differential sensitivity toward the repulsive activity of posterior tectal membranes, with temporal axons being repelled and nasal axons being insensitive, thus growing out in a random fashion. Therefore, in this kind of experiment, the ideal case of an internal control is provided.

If analyzing guidance properties of novel membrane fractions of different tissue sources, we recommend the following set of controls:

1. Prepare striped carpets with both stripes containing the same membrane fragments; this should result in random outgrowth.

2. To selectively inactivate the activity of membrane fractions under investigation, heat inactivation can be employed ${ }^{1}$. For example, by incubating membrane solutions at $63{ }^{\circ} \mathrm{C}$ for 8 min, all guidance activity can be eliminated ${ }^{1}$.

3. The order of arranging membrane fractions into the sets of first and second stripes should be reversed; with this control, axons being, for example, repelled by membrane compounds in the set of first stripes (thus growing preferentially on the set of second stripes) should now - in the reverse order-be repelled by the (unlabeled) second stripes, thus growing preferentially on the labeled set of first stripes.

4. Reduce receptor-ligand interaction of axons with carpet molecules by exogenously adding purified receptors or ligands into the medium ${ }^{36,38}$.

\section{Controls in the modified version of the stripe assay}

Typically, when preparing a set of carpets (e.g., 10-12), at least 3-4 carpets should be designated for the control experimental situation. Controls to be included in the modified version of the stripe assay are the following:

1. Prepare carpets with both sets of stripes containing control molecules (e.g., Fc versus Fc; see Fig. 3e). Also, carpets with both sets of stripes containing the molecule under investigation should randomize the guidance decision of axons (see also ref. 4).

2. Reverse the order of the sets of first and second stripes (see above).

3. Reduce receptor-ligand interaction of axons with carpet molecules by exogenously adding purified receptors or ligands into the medium (see above). 
(x) Wash by slowly rinsing the matrices with $500 \mu$ HBSS employing either the Hamilton syringe or the vacuum method (as described in Step viii).

(xi) Remove excess HBSS and matrix from the Petri dish by lifting the matrix starting at the upper right corner opposite to the injection channel (Fig. 2f,g).

(xii) Preparation of the second set of stripes. Immediately after removing the matrix, add $100 \mu$ of second stripe solution to the previously labeled area of stripes (labeled in Step 1B(vii), also see Fig. $\mathbf{2 h}$ ).

$\triangle$ CRITICAL STEP After removing the matrix of one dish, immediately add second stripe solution to prevent drying out of first stripes. Do one dish at a time.

(xiii) You may find it helpful to encircle the stripes with a Pap-pen (approximately $2 \mathrm{~cm}$ in diameter; Fig. $2 \mathrm{~h}$ ) to reduce the total volume of cell culture medium needed; however, this is an optional step.

(xiv) Incubate all dishes for $30 \mathrm{~min}$ at $37{ }^{\circ} \mathrm{C}$.

(xv) Remove second stripe solution as much as possible but not completely to prevent drying out of the carpet and wash once with HBSS.

(xvi) Incubate stripes with $100 \mu \mathrm{l}$ laminin in HBSS for $2-3 \mathrm{~h}$ at $37{ }^{\circ} \mathrm{C}\left(20 \mu \mathrm{g} \mathrm{ml}^{-1}\right)$. Laminin provides an overall outgrowthpromoting substrate, which is necessary, particularly when testing repulsive molecules; laminin incubation might be skipped depending on the molecule under investigation. Also other extracellular matrix components such as fibronectin or collagen can be tried. During laminin incubation, prepare cells to be examined. Note that this step is optional and might be omitted while testing novel proteins for their guidance activity.

(xvii) Wash stripes once with HBSS.

(xviii) Add $500 \mu$ culture medium and keep dishes in the incubator until cells are ready to be plated.

\section{Plating of cells and explants on carpets}

2| For plating dissociated single cells (e.g., mouse hippocampal neurons), spread $10^{4}$ cells per stripe area. Mouse postnatal hippocampal neurons can be prepared according to a previously published protocol ${ }^{37}$. When using explants (e.g., dorsal root ganglia, vomeronasal organ, Xenopus or zebrafish retina), distribute 10-20 explants on one carpet. To allow radial outgrowth of nerve fibers from the explant, sharp tungsten needles should be employed to cut tissue into squares or rectangles (average diameter 300-500 mm). Alternatively, as in the case of chick RGC explants (see ref. 2), E6 retinae can be flat-mounted on nitrocellulose filters and cut into $200-300 \mathrm{~mm}$ wide strips using a tissue chopper. Two of these retinal explants can be arranged on one carpet.

3| Incubate cultures for 24-48 h. If desired, perform standard immunocytochemistry employing, for example, a tubulin-specific antiserum or fluorescent labeling of RGCs with $\mathrm{DiI}^{2}$.

? TROUBLESHOOTING

\section{TIMING}

To prepare 10-12 carpets either by the original or by the modified version of the stripe assay, it takes approximately $4-5 \mathrm{~h}$.

\section{? TROUBLESHOOTING}

Troubleshooting advice can be found in Table 1.

TABLE 1 | Troubleshooting table.

\begin{tabular}{ll}
\hline Problem & Possible reason \\
\hline $\begin{array}{l}\text { No or fuzzy white intermediate } \\
\text { phase in the sucrose gradient }\end{array}$ & Amount of starting material too low or high \\
& $\begin{array}{l}\text { Generally, membranes derived from transfected } \\
\text { tissue culture cells tend to result in less sharp } \\
\text { intermediate phases }\end{array}$
\end{tabular}

Poor outgrowth of axons

No guidance decision
Pap-pen might be cytotoxic Membranes/proteins used are poor substrates for cell motility

Proteins in membrane fractions might be degraded

\section{Solution}

Use 40-60 mg of tissue as starting material

For tissue culture cells, use four dishes of $10-\mathrm{cm}$ diameter with approximately $1.5-3 \times 10^{6}$ cells for each of transfected cells and parental cell line as starting material

Skip or try a different one from another company Try to add laminin or other growth-promoting substrates (e.g., fibronectin)

Reduce the concentration of membranes or purified proteins

Add protease inhibitor freshly to $\mathrm{HB}$

Work quickly through preparation procedure Do not store membrane fractions for too long (>2-3 months) and measure activity again 
TABLE 1 | Troubleshooting table (continued).

\begin{tabular}{ll}
\hline Problem & Possible reason \\
\hline Lot of commercially available purified proteins \\
does not work \\
Molecules do not adhere to surface \\
Molecules do not function as guidance cue in \\
substrate-bound form or not at all
\end{tabular}

Stripe pattern is weak, stripe borders are not sharp

Unspecific guidance decision in control stripe assay (mostly in modified stripe assays)
In modified stripe assay:

Matrix did not adhere to dish evenly and firmly Matrix dried out

In original stripe assay:

Nucleopore membrane did not cover stripe margins

Nucleopore filter dried out

Drying out of first stripe pattern leads to physical barriers at stripe borders

Anti-human IgG, fc-specific antibody aggregated

Serum (e.g., different lot) used for growth medium
Solution

Check lot of purified proteins on, for example, SDS-PAGE or in collapse assay

Check with an antibody directed against the molecule for adherence to surface

Try different guidance tests suitable for secreted molecules (e.g., collagen co-culture assay, turning assay)

Make sure no air bubbles are between matrix and dish

Matrices have to be completely dry before use Clean matrices after 2-3 experiments by removing, for example, dust with transparent tape from striped surface

Have second stripe solution already at hand when removing matrix

Make sure nucleopore filter overlaps the margins of white and blue matrices; cut larger nucleopore filter pieces Make sure nucleopore membranes are arranged in the right orientation (cut left top corner; shiny side of membrane up) onto suction filter Work quickly, transfer nucleopore membranes rapidly on prepared dishes with PBS drop between sucking steps

Work quickly through the protocol

Check the quality of stripes under fluorescence before use Spin down antibody $\left(1-2 \mathrm{~min}, 13,000 \mathrm{~g}, 4^{\circ} \mathrm{C}\right)$

Reduce the concentration of purified protein and control protein; vary the level of 'clustering' (add less anti-Fc antibody)

Use serum-free medium

Try various serum batches

\section{ANTICIPATED RESULTS}

Images depicting typical anticipated results are given in Figure 3. Figure 3a shows the typical pattern of alternating stripes derived from membrane fractions of the anterior and the posterior chicken optic tectum, respectively. Posterior membranes are labeled with rhodamin-coupled beads. Figure $\mathbf{3 b}$ shows alternating stripes consisting of purified ephrin-A5-Fc (labeled with FITC-conjugated anti-human IgG, Fc-specific antibodies) versus Fc alone (dark stripes). Note that stripe borders using the modified version of stripe assay appear sharper compared to the original version (see Fig. 3a). The circle indicates the position and size of an explant cultured on top of the carpet. Figure 3c shows a stripe assay experiment using alternating stripes of anterior and posterior tectal membranes (original version), cultured with RGC explants (labeled in green). Axons of the temporal retina are strongly repelled by cues present in the posterior membranes (labeled in red). Nasal axons growing in a random fashion serve as an internal control in this type of experiment. Figure $\mathbf{3} \mathbf{d}$ shows a stripe assay experiment using purified ephrinA5-Fc (modified version). Ephrin-A5-Fc-containing stripes (in red) are alternating with Fc-only-containing stripes (not marked). In this setup, both temporal and nasal RGC axons (in green) are repelled by ephrin-A5-Fc, thus growing preferentially on Fc-containing stripes. Note that owing to fasciculation, not the entire stripe width is occupied by RGC axons.

Figure $3 e$ shows a control stripe assay experiment using carpets with both stripes consisting of Fc alone. This important control-to be included in every stripe assay experiment-reveals unbiased random outgrowth of axons. 
ACKNOWLEDGMENTS B.K. is supported by the Emmy Noether program of the Deutsche Forschungsgemeinschaft (DFG), grants by the SFB446 and Tübingen University. A.N. acknowledges support by the DFG (nos. 120/12-2 and SFB446) and the Fonds der Chemischen Industrie. We thank Susanne Lang, Claudia Handwerker and Jürgen Jung for technical improvements provided to the stripe assay technique and Jürgen Berger, Heinz Schwarz and Gertrud Scheer for their help in image acquisition. We thank Christopher Jarvis for his comments on the manuscript.

COMPETING INTERESTS STATEMENT The authors declare no competing financial interests.

Published online at http://www.natureprotocols.com

Rights and permissions information is available online at http://npg.nature.com/ reprintsandpermissions

1. Walter, J., Henke-Fahle, S. \& Bonhoeffer, F. Avoidance of posterior tectal membranes by temporal retinal axons. Development 101, 909-913 (1987).

2. Walter, J., Kern-Veits, B., Huf, J., Stolze, B. \& Bonhoeffer, F. Recognition of position-specific properties of tectal cell membranes by retinal axons in vitro. Development 101, 685-696 (1987).

3. McLaughlin, T. \& $0^{\prime}$ Leary, D.D. Molecular gradients and development of retinotopic maps. Annu. Rev. Neurosci. 28, 327-355 (2005).

4. Vielmetter, J., Stolze, B., Bonhoeffer, F. \& Stuermer, C.A. In vitro assay to test differential substrate affinities of growing axons and migratory cells. Exp. Brain Res. 81, 283-287 (1990).

5. Monschau, B. et al. Shared and distinct functions of RAGS and ELF-1 in guiding retinal axons. EMBO J 16, 1258-1267 (1997).

6. Feldheim, D.A. et al. Genetic analysis of ephrin-A2 and ephrin-A5 shows their requirement in multiple aspects of retinocollicular mapping. Neuron 25, 563-574 (2000).

7. Drescher, U. et al. In vitro guidance of retinal ganglion cell axons by RAGS, a $25 \mathrm{kDa}$ tectal protein related to ligands for Eph receptor tyrosine kinases. Cell 82, 359-370 (1995).

8. Knoll, B. et al. Serum response factor controls neuronal circuit assembly in the hippocampus. Nat. Neurosci. 9, 195-204 (2006).

9. Knoll, B., Zarbalis, K., Wurst, W. \& Drescher, U. A role for the EphA family in the topographic targeting of vomeronasal axons. Development 128, 895-906 (2001).

10. Mann, F., Zhukareva, V., Pimenta, A., Levitt, P. \& Bolz, J. Membrane-associated molecules guide limbic and nonlimbic thalamocortical projections. J. Neurosci. 18, 9409-9419 (1998).

11. Savaskan, N.E. et al. Myelin does not influence the choice behaviour of entorhinal axons but strongly inhibits their outgrowth length in vitro. Eur. J. Neurosci. 11 316-326 (1999).

12. Wizenmann, A. \& Bahr, M. Growth characteristics of ganglion cell axons in the developing and regenerating retino-tectal projection of the rat. Cell Tissue Res. 290, 395-403 (1997).

13. Monnier, P.P., Sierra, A., Schwab, J.M., Henke-Fahle, S. \& Mueller, B.K. The Rho/ ROCK pathway mediates neurite growth-inhibitory activity associated with the chondroitin sulfate proteoglycans of the CNS glial scar. Mol. Cell. Neurosci. 22, 319-330 (2003).

14. Oertle, T. et al. Nogo-A inhibits neurite outgrowth and cell spreading with three discrete regions. J. Neurosci. 23, 5393-5406 (2003).

15. Bahr, M. \& Schwab, M.E. Antibody that neutralizes myelin-associated inhibitors of axon growth does not interfere with recognition of target-specific guidance information by rat retinal axons. J. Neurobiol. 30, 281-292 (1996).

16. Yates, P.A., Roskies, A.L., McLaughlin, T. \& 0'Leary, D.D. Topographic-specific axon branching controlled by ephrin-As is the critical event in retinotectal map development. J. Neurosci. 21, 8548-8563 (2001).
17. Pozas, E. et al. Age-dependent effects of secreted Semaphorins $3 A$, 3F, and $3 E$ on developing hippocampal axons: in vitro effects and phenotype of Semaphorin $3 \mathrm{~A}$ (-/-) mice. Mol. Cell. Neurosci. 18, 26-43 (2001).

18. Nguyen-Ba-Charvet, K.T. et al. Sensory axon response to substrate-bound Slit2 is modulated by laminin and cyclic GMP. Mol. Cell. Neurosci. 17, 1048-1058 (2001).

19. Snow, D.M., Lemmon, V., Carrino, D.A., Caplan, A.I. \& Silver, J. Sulfated proteoglycans in astroglial barriers inhibit neurite outgrowth in vitro. Exp. Neurol. 109, 111-130 (1990).

20. Snow, D.M. \& Letourneau, P.C. Neurite outgrowth on a step gradient of chondroitin sulfate proteoglycan (CS-PG). J. Neurobiol. 23, 322-336 (1992).

21. Schafer, M., Brauer, A.U., Savaskan, N.E., Rathjen, F.G. \& Brummendorf, T. Neurotractin/kilon promotes neurite outgrowth and is expressed on reactive astrocytes after entorhinal cortex lesion. Mol. Cell. Neurosci. 29, 580-590 (2005).

22. Wang, H.U. \& Anderson, D.J. Eph family transmembrane ligands can mediate repulsive guidance of trunk neural crest migration and motor axon outgrowth. Neuron 18, 383-396 (1997).

23. Cohen, R.I., Rottkamp, D.M., Maric, D., Barker, J.L. \& Hudson, L.D. A role for semaphorins and neuropilins in oligodendrocyte guidance. J. Neurochem. 85, 1262-1278 (2003).

24. Moreau-Fauvarque, C. et al. The transmembrane semaphorin Sema4D/CD100, an inhibitor of axonal growth, is expressed on oligodendrocytes and upregulated after CNS lesion. J. Neurosci. 23, 9229-9239 (2003).

25. Nasarre, P. et al. Semaphorin SEMA3F has a repulsing activity on breast cancer cells and inhibits E-cadherin-mediated cell adhesion. Neoplasia (NY) 7, 180-189 (2005).

26. Kolpak, A., Zhang, J. \& Bao, Z.Z. Sonic hedgehog has a dual effect on the growth of retinal ganglion axons depending on its concentration. J. Neurosci. 25, 3432-3441 (2005).

27. Monnier, P.P. et al. RGM is a repulsive guidance molecule for retinal axons. Nature 419, 392-395 (2002).

28. Rodriguez, J. et al. SFRP1 regulates the growth of retinal ganglion cell axons through the Fz2 receptor. Nat. Neurosci. 8, 1301-1309 (2005).

29. Mack, T.G., Koester, M.P. \& Pollerberg, G.E. The microtubule-associated protein MAP1B is involved in local stabilization of turning growth cones. Mol. Cell. Neurosci. 15, 51-65 (2000).

30. Hahn, C.M. et al. Role of cyclin-dependent kinase 5 and its activator P35 in local axon and growth cone stabilization. Neuroscience 134, 449-465 (2005).

31. von Philipsborn, A. et al. Microcontact printing of axon guidance molecules for generation of graded patterns. Nat. Protocols 1, 1322-1328 (2006).

32. Weinl, C., Drescher, U., Lang, S., Bonhoeffer, F. \& Loschinger, J. On the turning of Xenopus retinal axons induced by ephrin-A5. Development 130, 1635-1643 (2003).

33. Hornberger, M.R. et al. Modulation of EphA receptor function by coexpressed ephrinA ligands on retinal ganglion cell axons. Neuron 22, 731-742 (1999).

34. Knoll, B. \& Drescher, U. Ephrin-As as receptors in topographic projections. Trends Neurosci. 25, 145-149 (2002).

35. Kullander, K. \& Klein, R. Mechanisms and functions of Eph and ephrin signalling. Nat. Rev. Mol. Cell Biol. 3, 475-486 (2002).

36. Rashid, T. et al. Opposing gradients of ephrin-As and EphA7 in the superior colliculus are essential for topographic mapping in the mammalian visual system. Neuron 47, 57-69 (2005).

37. Goetze, B., Grunewald, B., Kiebler, M.A. \& Macchi, P. Coupling the iron-responsive element to GFP - an inducible system to study translation in a single living cell. Sci. STKE 2003, PL12 (2003).

38. Ciossek, T. et al. Eph receptor-ligand interactions are necessary for guidance of retinal ganglion cell axons in vitro. Eur. J. Neurosci. 10, 1574-1580 (1998). 